\title{
Estimating the sustainable harvesting and the stable diameter distribution of European beech with projection matrix models
}

\author{
Ignacio LóPEZ ${ }^{\mathrm{a} *}$, Sigfredo Francisco ORTUÑo ${ }^{\mathrm{a}}$, Ángel Julián MARTín ${ }^{\mathrm{a}}$, Carmen Fullana ${ }^{\mathrm{b}}$

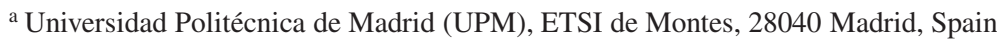 \\ ${ }^{\mathrm{b}}$ Universidad Pontificia de Comillas, Alberto Aguilera, 23, 28015 Madrid, Spain
}

(Received 20 October 2006; accepted 21 February 2007)

\begin{abstract}
We present a projection matrix model to estimate the sustainable harvest rates and the stable diameter distributions of three qualities of European beech in the Spanish province of Navarre. Considering a period of 10 years and the diameter growth, trees were grouped into five classes: $(0,10),(10,20),(20,30),(30,40)$ and over $40 \mathrm{~cm}$. The transition probabilities were calculated assuming an approximation by splines to the diameter growth curves and uniform distributions for the diameters in each class. A condition for sustainable harvesting, leading to reach in each harvest the stable diameter distribution, was introduced. The results obtained suggest that, for each projection and depending on the quality, harvest rates in the range $18.8-37.5 \%$ for recruitments in the range $200-840$ stems/ha, may be sustained without risk of a population reduction. Finally, the stable diameter distributions in relation to the recruitment were also obtained for each quality.
\end{abstract}

sustainability / projection matrix model / European beech / harvesting / stable diameter distribution

Résumé - Estimation de la récolte renouvelable et de la distribution stable du diamètre du hêtre par une projection de modèles matriciels. Nous présentons une projection de modèle matriciel pour estimer les taux de récolte renouvelable et les distributions stables de diamètre de trois qualités de hêtre dans la province espagnole de Navarre. La croissance en diamètre sur une période de 10 ans a été prise en compte pour des arbres regroupés en cinq classes de diamètre : $(0,10),(10,20),(20,30)$ et au-delà de $40 \mathrm{~cm}$. Les probabilités ont été calculées en adoptant une approximation par aboutement des courbes de diamètre et les distributions uniformes pour les diamètres dans chaque classe de diamètre. Une condition pour une récolte renouvelable, importante pour atteindre une distribution stable de diamètre, a été introduite. Les résultats obtenus suggèrent, que pour chaque projection et en relation avec la qualité, un taux de récolte se situe dans une variation de 18,8 à 37,5\% pour un recrutement dans une variation de 200 à 840 arbres à 1 'hectare, peut être supporté sans risque pour une réduction de population. Finalement, des distributions stables de diamètre en relation avec le recrutement ont été obtenues pour chaque qualité.

renouvelable / projection de modèle matriciel / hêtre / récolte / distribution stable de diamètre

\section{INTRODUCTION}

Population projection matrix models, introduced by Leslie [17], and modified by Lefkovitch [18] by grouping organisms in terms of stage categories rather than age categories, have been widely applied to analyze the evolution, management, harvest, etc., of tree populations (many examples are shown in Zuidema [40] and Caswell [3] and, more recently, in Van Mantgem et al. [38]). These models are defined by the standardized finite difference linear system of equations $N(t+1)=A N(t)$, where $N(t)$ and $N(t+1)$ are column vectors containing the number of stems/ha within each diameter class at time $t$ and $t+1$, respectively, and $A$ is a square primitive matrix containing, for each time step, transition probabilities between adjacent classes and individual recruitments. The population growth rate is the dominant eigenvalue $\lambda_{0}$ of matrix $A$ and, by asymptotic analysis (long-term behaviour) we know that when $\lambda_{0}>1$ the total number of stems/ha of the population of trees increases exponentially over time (unless harvests

* Corresponding author: i.lopez@upm.es are conducted), when $\lambda_{0}<1$ the population is projected to decay until extinction, and when $\lambda_{0}=1$ a stable distribution is obtained, which is proportional to $W_{0}$, right eigenvector of $A$ corresponding to $\lambda_{0}$.

Following Sterba [34], there are mainly two types of diameter distributions considered as stable by the forest literature. First, de Liocourt's semi-logarithmic dbh-distribution [7], with the extensions by Susmel [35], and Cancino and von Gadow [4]. The second by Schütz [31] have shown that a stable diameter distribution needs not necessarily to have a semilogarithmic form, but rather has to fulfil the condition that, for each diameter class, the number of trees incoming from the next class below must equal the number of trees growing out from it to the next diameter class above, plus the number of trees harvested (including natural mortalities) in the class. In general, the concept of stability is closely associated with the concept of perturbation: a system is considered stable if it always returns to a reference position (equilibrium) after small perturbations (otherwise, the system is said to be unstable). Under these conditions, we define the diameter distribution to be stable if it neither increases in size nor changes in 
structure, that is, if the number of stems/ha within each diameter class remains constant over time. These stable distributions are closely dependent on recruitment, removal and stem migration throughout the dbh-classes over time [33].

In this context, the main purpose of this paper is to estimate the long-term sustainable harvest rates and the stable diameter distributions of uneven-aged managed beech (Fagus Sylvatica L.) stands in Navarre (Northeastern Spain), using projection matrix models.

\section{MATERIALS AND METHODS}

\subsection{Study area and first data}

Beech is an important tree species in Europe [37]. Particularly in Spain, according to data of the Second National Forest Inventory [13], Fagus Sylvatica L. occupies, as dominant species, a surface of $389654 \mathrm{ha}$, of which 134945 are located in the province of Navarre [11]. Hence we have chosen data on the Fagus Sylvatica L. growth and yield tables in Navarre [19], in order to build a projection matrix model that would enable us to estimate the long-term sustainable harvest rates and the stable diameter distributions in these managed pure uneven-aged stands. To build these tables, data about diameter at breast height, stems/ha, mean and dominant height, basal area, volume and diameter growth, were collected throughout the year 1996 from a network of 86 rectangular sample plots ranged in area from 625 to $1500 \mathrm{~m}^{2}$, representing a wide variety of climatic and soil conditions. These average data were classified according to the growth level into five qualities (site index classes), I to V, from which we have extracted the first three for our models: I (faster diameter growth, 22 sample plots), II (medium diameter growth, 28 sample plots) and III (slower diameter growth, 24 sample plots). These three qualities were defined according to the dominant height reached at the reference age of 100 years, being respectively 27,24 and $21 \mathrm{~m}$ (Qualities IV and V were less commercially feasible). The diameter growth curves along the 180 years of our study, obtained by means of regression analysis, are shown in Figure 1 [19].

\subsection{The model}

The model is defined by means of a matrix of transition probabilities from several diameter classes from time $t$ to time $t+1$. Since the harvesting operations in the study area generally took place every 10 years, this was the time period or range of the projection intervals adopted in the model. As for the dimension, the use of a small matrix dimensionality is generally recommended for projection matrix models concerning slow-growing tree species [27], due to the fact that the dominant eigenvalues are scarcely influenced by the matrix size. Thus, considering the time period defined and the diameter growth curves corresponding to Qualities I to III, trees have been grouped in the model into five diameter classes: $(0,10),(10,20),(20,30),(30,40)$, and over $40 \mathrm{~cm}$, so that an individual tree in class- $i$ can either remain in class $-i$ or progress to class- $(i+1)$ over the projection interval $(t$, $t+1)$. The number of trees in each class changes each projection interval, as some are harvested, some remain in the same diameter class, and others grow over the boundary into the next diameter class. Under these conditions, let $p_{i}$ be the probability that an individual tree in class- $i$ at time $t$ will be in class- $(i+1)$ at time $t+1$ of projection, $r_{i}$ the

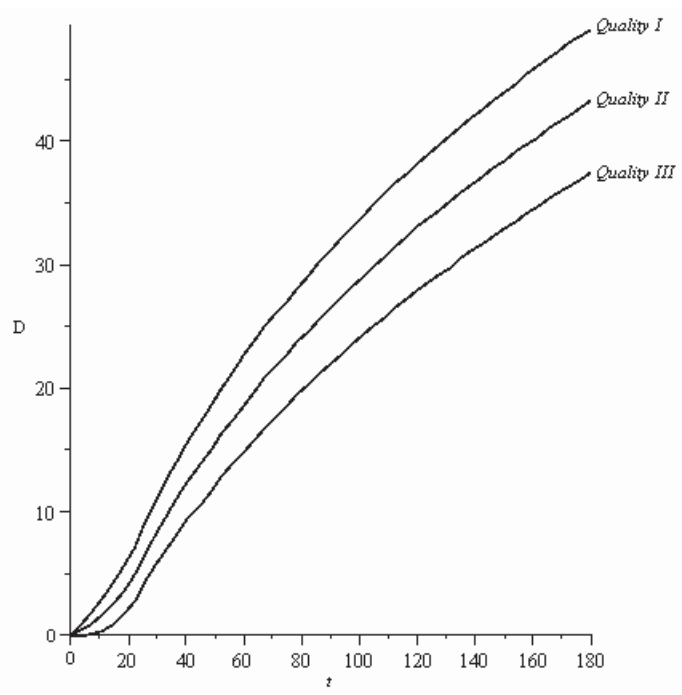

Figure 1. Diameter growth curves for each quality (tree diameter D in $\mathrm{cm}$, $\mathrm{t}$ in years).

recruitment coefficients, that is to say, the number of offsprings living at time $t+1$ of projection that were produced in the interval $(t, t+1)$ by an average tree in class- $i$ at time $t, h_{i}$ the proportion of harvested trees in class- $i, N_{i}(t)$ and $N_{i}(t+1)$ the stem densities $\left(\right.$ ha $\left.^{-1}\right)$ in class- $i$ at the initial and final times of projection. Analyzing the dynamics of the projections, we can see that the model is defined by the finite difference homogeneous linear system

$$
N(t+1)=A(I-H) N(t),
$$

where

$$
A=\left(\begin{array}{llllr}
1-p_{1} & r_{2} & r_{3} & r_{4} & r_{5} \\
p_{1} & 1-p_{2} & 0 & 0 & 0 \\
0 & p_{2} & 1-p_{3} & 0 & 0 \\
0 & 0 & p_{3} & 1-p_{4} & 0 \\
0 & 0 & 0 & p_{4} & 1
\end{array}\right)
$$

is the transition matrix, $I$ is the identity matrix, $H=\operatorname{diag}\left(h_{1}, h_{2}, h_{3}, h_{4}, h_{5}\right)$ is a diagonal matrix with the harvest rates (including natural mortalities), $N(t)$ and $N(t+1)$ are column vectors with the stem densities at the initial and final times of projection.

It is well known $[5,9,24]$ that when a nonnegative matrix, such as the projection matrices $A$ (without harvesting) or $A(I-H)$ (with harvesting), is primitive, the long-term dynamics of the population is always proportional to a right eigenvector corresponding to the dominant eigenvalue of this matrix, independently of the initial population $N(0)$.

The starting hypotheses for the model were the following: (a) the forest is in a steady state; (b) the diameter growth curves for each Quality I to III along the 180 years of the study are defined by Figure 1 ; (c) the probability distribution for the diameter of the trees, for each diameter class, is the uniform (rectangular); (d) the harvesting operations will be carried out according to the selection system at the beginning of every projection interval (if these operations were performed at the end, then the model would be $N(t+1)=(I-H) A N(t))$.

The calculations were run using Maple version 10.0 software [21]. 
Table I. Diameter projections for computing the transition probabilities.

\begin{tabular}{lcc}
\hline & Initial diameter $(\mathrm{cm})$ & Diameter projected to 10 years $(\mathrm{cm})$ \\
\hline \multirow{4}{*}{ Quality I } & 0 & 2.532125 \\
& 10 & 14.485412 \\
& 20 & 23.407979 \\
& 30 & 32.521245 \\
Quality II & 40 & 41.915034 \\
& 0 & 1.369245 \\
& 10 & 13.568316 \\
& 30 & 22.763328 \\
& 40 & 32.090842 \\
\multirow{4}{*}{ Quality III } & 0 & 41.597509 \\
& 10 & 0.237231 \\
& 20 & 12.960141 \\
& 30 & 22.178321 \\
& 40 & 31.683320 \\
\hline
\end{tabular}

\subsection{Input estimation}

To estimate the transition probabilities $p_{i}$ between each consecutive pair of diameter classes, for every 10 year interval, the model first uses curve fitting commands of Maple, to build a cubic splines approximation in the interval $(0,180)$ years to the previously mentioned (Fig. 1) diameter growth curves. By means of this approximation, and for each quality, we have determined the diameter at the end of each projection of 10 years of trees with $0,10,20,30$ or $40 \mathrm{~cm}$ at the beginning. Thus, bearing in mind hypothesis (c), it is easy to see that the transition probabilities from class- $i$ to class- $(i+1)$, that is to say, from interval $(10(i-1), 10 i)$ to interval $(10 i, 10(i+1))$, are given by

$$
p_{i}=\left(D_{i}-10 i\right) /\left(D_{i}-D_{i-1}\right), \text { for } i=1,2,3,4,
$$

where $D_{i}$, for $i=0,1,2,3,4$, is the diameter at the end of the projection interval for a tree with a diameter equal to $10 i$ at the beginning. We have summarized these calculations in Tables I and II.

As for recruitment (natural recruitment), Fagus Sylvatica has been classified as the most shade-tolerant broadleaf tree species in Europe [25], and its regeneration under its own canopy has been considered rather easy. But seedling growth under low light conditions is strongly reduced, mainly due to the great capacity of light assimilation that adult Fagus trees possess $[6,20]$. Previous investigations have shown that, although the initial establishment of seedlings is possible even in closed dense beech stands, their later development will be difficult if the basal area of the trees with $\mathrm{dbh}>17.5 \mathrm{~cm}$ is greater than $18 \mathrm{~m}^{2}$ [22,32]. Therefore, Fagus regeneration takes place mostly in canopy gaps and less dense canopy zones, in which young trees reach often large densities [16].

Beech generally regenerates by seeds which, under favourable ecological and technical conditions (absence of severe frost and drought, weak predation, appropriate working of the soil, weak herbaceous concurrence, enough solar radiation, etc.) germinate giving place to thousands of seedlings [36].

As regards global recruitment, we should bear in mind what previous investigations have shown: (a) in Spain the Second National
Forest Inventory [13] only considers normal recruitments those between 501 and 2000 stems/ha; (b) in the pure beech plenter forest of Langula (Thuringia basin, Eastern Germany), under the threshold of 99 stems/ha in the $(8,12)$ diameter class, the recruitment was insufficient to maintain on the long run the structural stability of the stand, and it is necessary to reverse the tendency by reducing standing volume [33]; (c) a 10 years (1981-1991) study on beech natural regeneration carried out in three sample plots $(87 \%, 73 \%, 70 \%$ of canopy closure respectively, 85 year old stand) in the semi-natural beech forests of the Carpathians has shown that seedling survival was the lowest in the most shaded plot for all time steps studied but, even in this case, the number of 11 year old seedlings (which survived 10 years) was 27000 per ha (in 1991), and in the other two plots 43700 and 53200 seedlings per ha, respectively. It has also shown that height growth was not different in the first five years, but later the effect of light was traced [30]; (d) after a big beech mast in 1976, the regeneration development of a beech stand (at that time 130 years old) in the Solling Mountains (Germany) was observed on a typical low-mountain range site for a period of 11 years. Beech regeneration developed from an average density of 80 to 90 seedlings $/ \mathrm{m}^{2}$ in the first year, to a young wood with 10 plants $/ \mathrm{m}^{2}$ after eleven years. At that time regeneration had reached an average height of about one meter, some plants, however, had already reached more than two meters in height. Experiments concerning the effect of high plant densities on the plants themselves were made in 1982 and 1987. As might be expected, high plant densities had a stronger influence on growth in 11 years old young woods than in 6 years old ones [8].

Summarizing, under favourable conditions, beech regeneration and future development of seedlings seem to be guaranteed, but the growth of the recruitment trees in the long-term depends strongly on stand density. In this regard, it will be proved in Section 2.5 that, for each pair $(R, G)$, where $G$ is the stand basal area and $R$ is the global amount of recruitment trees (which are maintained on the long-term), there exists only one stable diameter distribution.

\subsection{Harvesting strategy}

As we can see in (1), harvesting induces a perturbation in the model of natural growth of trees, which is

$$
N(t+1)=A N(t)
$$

modifying the natural transition matrix $A$ toward the perturbed $A(I-H)$. Thus, if the matrices $A$ and $A(I-H)$ are primitive, and whenever the dominant eigenvalue of matrix $A$ be $\lambda_{0}>1$, the long-term sustainable harvest rates can be determined as the proportion of trees removed in each class so that the dominant eigenvalue of matrix $A(I-H)$ be $\lambda=1$. There are, of course, many different removal strategies to satisfy this condition, and many other unable to do it. Some strategies, focussed on the last diameter class, are conditioned by the occurrence of discoloured red heartwood, whose probability increases as the harvest diameter increases [15]. The strategy implemented in this model is based on the following condition (C3), which leads to reach in each harvest the proportions of stems/ha in each class corresponding to the stable diameter distribution. Condition (C3), together with conditions (C1) and (C2), define the harvesting strategy for the model, and are formulated as follows:

(C1) A necessary condition to carry out the harvesting operations is $\lambda_{0}>1$ (since natural mortalities are not included in matrix $A$, this condition should be interpreted loosely). 
Table II. Transition probabilities between diameter classes for each quality.

\begin{tabular}{llll}
\hline & Quality I & Quality II & Quality III \\
\hline$(0,10) \rightarrow(10,20)$ & $\mathrm{P}_{1}=0.375245$ & $\mathrm{P}_{1}=0.292507$ & $\mathrm{P}_{1}=0.232662$ \\
$(10,20) \rightarrow(20,30)$ & $\mathrm{P}_{2}=0.381951$ & $\mathrm{P}_{2}=0.300525$ & $\mathrm{P}_{2}=0.236307$ \\
$(20,30) \rightarrow(30,40)$ & $\mathrm{P}_{3}=0.276657$ & $\mathrm{P}_{3}=0.224159$ & $\mathrm{P}_{3}=0.177098$ \\
$(30,40) \rightarrow(40, \rightarrow)$ & $\mathrm{P}_{4}=0.203862$ & $\mathrm{P}_{4}=0.168041$ & $\mathrm{P}_{4}=0.136363$ \\
\hline
\end{tabular}

(C2) For reasons of sustainability, the dominant eigenvalue $\lambda$ of matrix $A(I-H)$ should be $\lambda=1$.

(C3) Each harvest should lead to the stable diameter distribution of the stand, which is given by the right eigenvector $W_{0}$ corresponding to the dominant eigenvalue $\lambda_{0}$ of the matrix $A$.

Thus, by solving $A W_{0}=\lambda_{0} W_{0}$, we obtain $W_{0}$, yielding (proportional to) the following vector:

$$
\begin{aligned}
W_{0}= & \left(\left(\lambda_{0}-1\right)\left(\lambda_{0}-1+p_{2}\right)\left(\lambda_{0}-1+p_{3}\right)\left(\lambda_{0}-1+p_{4}\right),\right. \\
& p_{1}\left(\lambda_{0}-1\right)\left(\lambda_{0}-1+p_{3}\right)\left(\lambda_{0}-1+p_{4}\right), \\
& p_{1} p_{2}\left(\lambda_{0}-1\right)\left(\lambda_{0}-1+p_{4}\right), \\
& \left.p_{1} p_{2} p_{3}\left(\lambda_{0}-1\right), p_{1} p_{2} p_{3} p_{4}\right) .
\end{aligned}
$$

This vector defines the stable diameter distribution and, consequently, the long-term dynamics of the non harvested populations. On the other hand, and assuming that condition (C1) holds, conditions (C2) and $(\mathrm{C} 3)$ can be rewritten by means of the linear system $A H W_{0}=\left(\lambda_{0}-\right.$ 1) $W_{0}$. Thus, we obtain the sustainable harvest rates which allow us to reach in each harvest the stable diameter distribution by solving this determinate compatible linear system, yielding

$$
h_{1}=h_{2}=h_{3}=h_{4}=h_{5}=h=\frac{\lambda_{0}-1}{\lambda_{0}} .
$$

In this Equation (4), $\frac{1}{\lambda_{0}}$ has the interpretation of the proportion of trees that has to remain unharvested to retain stable diameter distribution.

Finally, by substituting (4) into $H$, we also have

$$
A(I-H)=(1-h) A=(I-H) A,
$$

which is, if conditions (C2) and (C3) hold, whether the harvesting operations are developed at the beginning of each period or at the end, we obtain the same results.

\subsection{Stable diameter distributions}

For this projection matrix model, as it was stated in 1 and 2.2, the stable diameter distribution is defined by the right eigenvector $W_{0}$ of the projection matrix $A$. Thus, it is independent of the harvesting strategy implemented by means of conditions (C1) to (C3). In order to obtain it, we can see from (3) that the components $\left(N_{1}, N_{2}, N_{3}, N_{4}, N_{5}\right)$ of $W_{0}$ verify

$$
\begin{array}{rl}
N_{i+1}=\frac{p_{i}}{\lambda_{0}-1+p_{i+1}} & N_{i}=l_{i} N_{i}, \\
\quad \text { for } i & i=1,2,3, \text { and } N_{5}=\frac{p_{4}}{\lambda_{0}-1} N_{4}=l_{4} N_{4},
\end{array}
$$

where $l_{i}=\frac{p_{i}}{\lambda_{0}-1+p_{i+1}}$, for $i=1,2,3$, and $l_{4}=\frac{p_{4}}{\lambda_{0}-1}$.
These Equations (6) may be easily rearranged in the light of the harvesting strategy implemented in the model to provide

$$
N_{i+1}=(1-h)\left[\left(1-p_{i+1}\right) N_{i+1}+p_{i} N_{i}\right],
$$

which has the following interpretation: the number of stems/ha for class $-(i+1)$ is $(1$-harvest rate $) \times($ Number of stems/ha that remain in this class- $(i+1)+$ ingrowth from class- $i)$.

Substituting $N_{i}$ (for $i=1,2,3$ ) from (6) into the equation of the basal area of the stand $(\mathrm{G})$, we get

$$
G=\frac{\pi N_{1}}{4}\left(D_{1}^{2}+D_{2}^{2} l_{1}+D_{3}^{2} l_{1} l_{2}+D_{4}^{2} l_{1} l_{2} l_{3}+D_{5}^{2} l_{1} l_{2} l_{3} l_{4}\right) .
$$

But, in the stable position, we know that $N(t+1)=\lambda_{0} N(t)$ which, for the first component, gives

$$
\left(1-p_{1}\right) N_{1}+\sum_{i=2}^{5} r_{i} N_{i}=\left(1-p_{1}\right) N_{1}+R=\lambda_{0} N_{1}
$$

where $R=r_{2} N_{2}+r_{3} N_{3}+r_{4} N_{4}+r_{5} N_{5}$ is the recruitment. By solving (8) for $N_{1}$, we obtain

$$
N_{1}=\frac{R}{\lambda_{0}-1+p_{1}}
$$

Substituting $N_{1}$ into (7), we finally arrive at

$$
G=\frac{\pi R}{4\left(\lambda_{0}-1+p_{1}\right)}\left(D_{1}^{2}+D_{2}^{2} l_{1}+D_{3}^{2} l_{1} l_{2}+D_{4}^{2} l_{1} l_{2} l_{3}+D_{5}^{2} l_{1} l_{2} l_{3} l_{4}\right) .
$$

This Equation (10) defines a surface which relates $\lambda_{0}$ and $R$ to $G$, and shows (among other things) that, for each pair $(R, G)$, there is only one stable diameter distribution. However, in order to maintain a stable population, it is necessary to secure the continuity of regeneration, with an adequate number of trees in the lower diameter classes, and the movement of these trees into higher classes, which is connected with the optimal stand basal area [14]. In this regard, it has been proved by means of experimental studies with irregular populations of beech, that the optimal basal area to maintain a continuous regeneration of the stand is about $22 \mathrm{~m}^{2} /$ ha [2, 22,32]. Although this threshold, above which recruitment trees might stop growing, could vary slightly depending on the site (in this regard, it may be useful the method proposed in [12]), it will be assumed for the estimations regarding the stable diameter distributions. Thus, substituting $\mathrm{G}=22 \mathrm{~m}^{2} /$ ha in (10), we obtain an equation which relates $R$ to $\lambda_{0}$, from which we can compute, for each $R$, a (real) value of $\lambda_{0}$. Finally, by substituting this $\lambda_{0}$ and the transition probabilities into (9) and (6), we get the corresponding stable diameter distribution, for each $R$.

\section{RESULTS}

Substituting $\mathrm{G}=22 \mathrm{~m}^{2} /$ ha and the transition probabilities calculated in Section 2.3 (Tab. II) into (10), we get the curves 


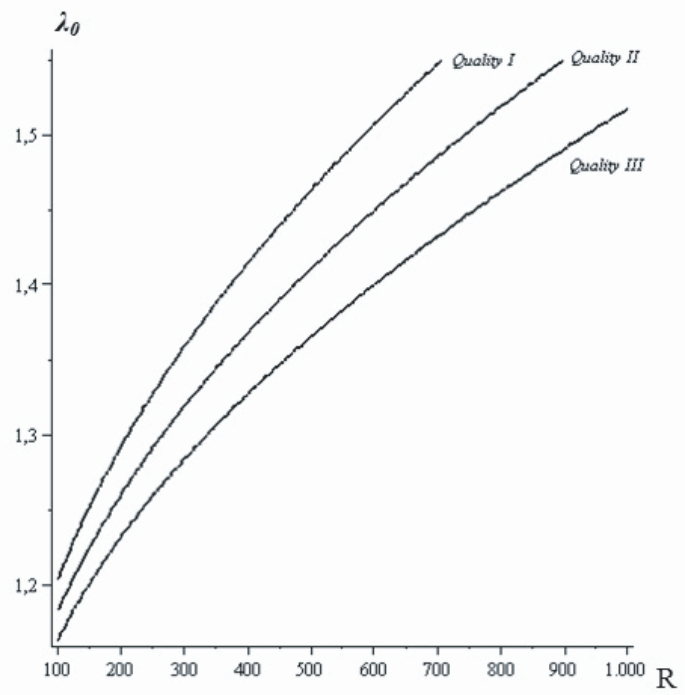

Figure 2. Dominant eigenvalue $\lambda_{0}$ in relation to the recruitment $R$, for each quality.

shown in Figure 2, which relate the recruitment $R$ to the dominant eigenvalue $\lambda_{0}$ of the transition matrix $A$, for each quality. For example, we can compute for $\lambda_{0}$ the values 1.292 (for Quality I), 1.260 (for Quality II) and 1.232 (for Quality III) when $R=200 \mathrm{stems} / \mathrm{ha}$, and these values are respectively $1.472,1.419,1.373$ when $R=520 \mathrm{stems} / \mathrm{ha}$, and $1.599,1.532$, 1.474 when $R=840$ stems/ha.

On the other hand, we know from (4) that $\lambda_{0}=\frac{1}{1-h}$. By substituting it into (10), we obtain the curves shown in Figure 3, which relate the recruitment $R$ to the sustainable harvest rates $h$ defined in 2.4, for each quality. For example, we can compute for $h$ the values $22.60 \%$ (for Quality I), $20.64 \%$ (for Quality II) and $18.81 \%$ (for Quality III) when $R=200$ stems/ha, and these values are respectively $32.07 \%, 29.52 \%, 27.14 \%$ when $R=520 \mathrm{stems} / \mathrm{ha}$, and $37.48 \%, 34.72 \%, 32.14 \%$ when $R=840$ stems $/$ ha.

Finally, the stable diameter distributions in relation to the recruitment are shown in Figures 4, 5 and 6. For example, we can compute (rounding) that these distributions are $(300,167$, $112,63,44)$ (for Quality I), $(361,189,117,61,40$ ) (for Quality II) and $(431,214,124,60,35)$ (for Quality III) when $R=$ 200 stems/ha, (614, 270, 138, 56, 24), (731, 297, 139, 53, 21), $(859,328,141,49,18)$ respectively when $R=520$ stems/ha, and $(862,329,144,49,17),(1019,358,142,46,14),(1189$, $390,141,41,12$ ) respectively when $R=840$ stems/ha (always from class $(0,10)$ to class $(40,+))$.

\section{DISCUSSION}

This study shows a method to estimate the sustainable harvest rates and the stable diameter distributions of three qualities of Fagus Sylvatica L. in the managed pure uneven-aged stands of Navarre (Spain), throughout a period of 180 years, with projection intervals of 10 years.

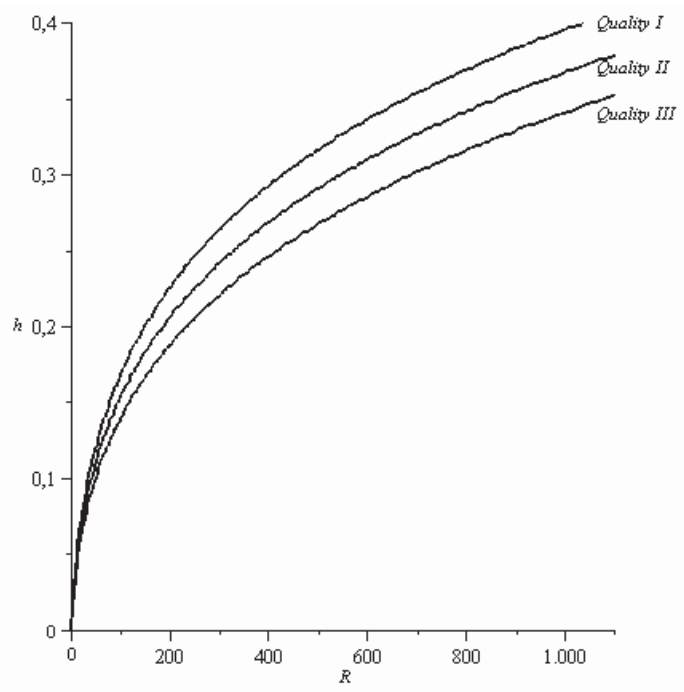

Figure 3. Sustainable harvest rates $h$ which give place in every harvest to the stable diameter distribution, in relation to the recruitment $R$, for each quality.

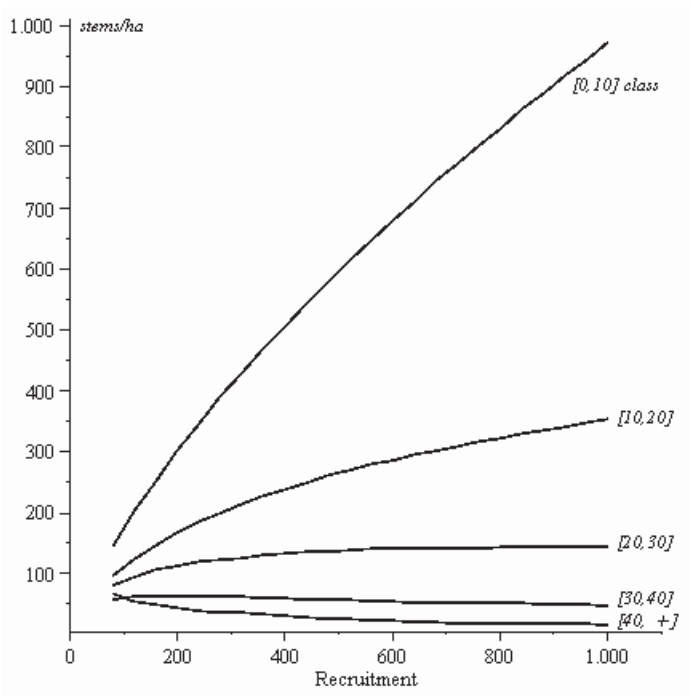

Figure 4. Stable diameter distribution in relation to the recruitment for Quality I.

In the absence of a detailed census of the trees in the study area, which would allow us to know the diameter of each tree belonging to each class as well as its evolution, the proposed method for the calculation of the transition probabilities is based on: (a) an approximation by cubic splines to the three average diameter growth curves calculated by means of regression analysis by Madrigal et al. [19] for Qualities I to III in the interval $(0,180)$ years. There are several methods for modelling individual-tree diameter growth (e.g. [10,23, 29,39]). In this model, we have used data from the Navarre beech stands growth and yield tables, which were contrasted with other data from works related to uneven-aged beech stands [31]. (b) An assumption of uniform (rectangular) distributions of 


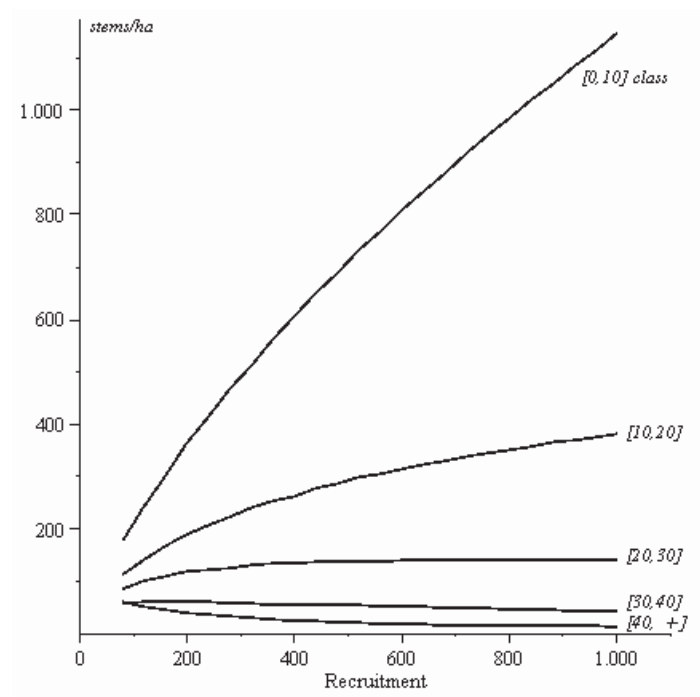

Figure 5. Stable diameter distribution in relation to the recruitment for Quality II.

probability for the diameters in each class. It is well known that uniform distribution is particularly useful for sampling from arbitrary distributions, and it has been widely applied to tree populations [26].

The results obtained for $\lambda_{0}$, which are in the range 1.232 1.599 for recruitments in the range $200-840$ stems/ha, are within the intervals corresponding to other tree species. In this regard, in two recent studies [27,40], the main characteristics of matrix models, for 35 woody species in the first and for 37 plant species (13 of them trees) in the second, were summarized. None of them was Fagus, but the variation range for $\lambda_{0}$ went from 0.977 to 1.589 , in the first case, and from 0.826 to 2.334 in the second. However, our results for $\lambda_{0}$, although within these intervals, were expected to be slightly high due to the fact that natural mortalities were absorbed by the harvesting rate $h$, not being incorporated into matrix $A$.

These natural mortalities, which depend mainly on tree age, intraspecific competition between trees located in close proximity [1], stand characteristics, and forestry practices, have been estimated from two sample plots, with areas 2500 and $3000 \mathrm{~m}^{2}$ respectively, in a 110 ha beech forest in Cantabria (Northern Spain, near the study area) in $26.38 \%$ for the dbh class $(2,4.9), 11.54 \%$ for the dbh class $(5,9.9), 4.38 \%$ for the dbh class $(10,29.9)$, and $1.43 \%$ for the dbh class $(30,80) \mathrm{cm}$ [28]. So, total harvest rates may be obtained by subtracting these natural mortalities from the harvest rates previously computed.

The stable diameter distributions were obtained in relation to the recruitment for a given basal area of the stand $\left(\mathrm{G}=22 \mathrm{~m}^{2} / \mathrm{ha}\right)$. We can see that, except for the distributions corresponding to Qualities I and II and a low level of recruitment, such as $R<100$ stems/ha approximately, where we have computed for the $(30,40)$ class densities slightly higher than for the $(40,+)$ class, all these distributions were reversed Jshaped, but not semi-logarithmic. In any case, the number of stems/ha is an increasing function of the recruitment for the

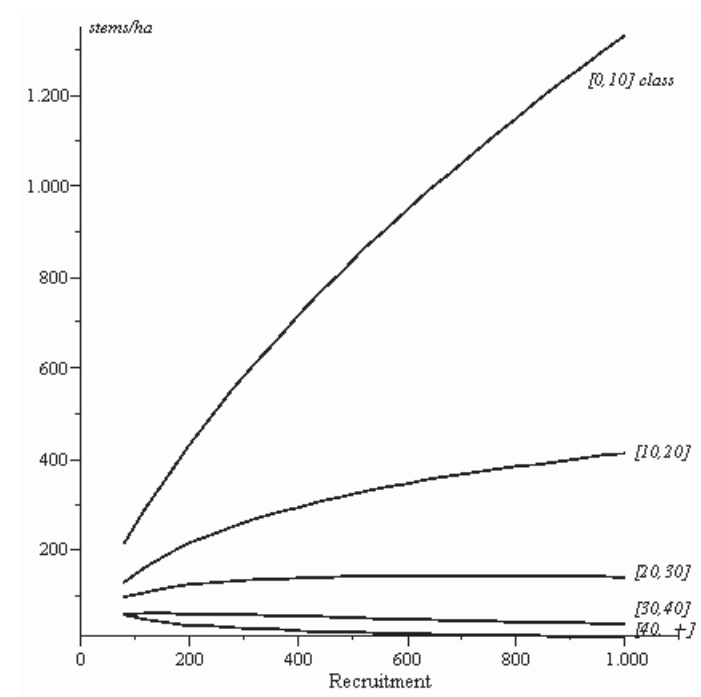

Figure 6. Stable diameter distribution in relation to the recruitment for Quality III.

first two classes, and a decreasing function of the recruitment for the last two.

Finally, as can be deduced from the previous sections, this model could be easily adapted to different situations, such as variations in the stand basal area, in the number of classes...

Acknowledgements: We would like to thank Dr. Salvador Rodríguez Nuero for revising the language of the manuscript.

\section{REFERENCES}

[1] Antonovics J., Levin D.A., The ecological and genetic consequences of density-dependent regulation in plants, Annual Rev. Ecol. Syst. 11 (1980) 411-452.

[2] Baar F., Gilisen J., Van Doren B., Cahier technique n ${ }^{\circ}$, Forêt Wallone, 2001.

[3] Caswell H., Matrix population models: construction, analysis, and interpretation, 2nd ed., Sinauer Associates Inc., Sunderland, MA, USA, 2001.

[4] Cancino J., von Gadow K., Stem number guide curves for unevenaged forests - development and limitations, in: von Gadow K., Nagel J., Saborowsky J. (Eds.), Continuous cover forestry, Kluwer Academic Press, Dordrecht, 2002, pp. 163-174.

[5] Cohen J.E., Ergodic theorems in demography, Bull. Am. Math. Soc. 1 (1979) 275-295.

[6] Collet C., Lanter O., Pardos M., Effects of canopy opening on height and diameter growth in naturally regenerated beech seedlings, Ann. For. Sci. 58 (2001) 127-134.

[7] De Liocourt F., De l'aménagement des sapinières, Bull. Soc. for. Franche-Comté et du Territoire de Belfort 4 (1898) 396-409, 645647.

[8] Dohrenbusch A., Die Verjüngungsentwicklung der Buche (Fagus silvatica L.). Bericht einer langfristigen Beobachtung im Solling, Schriften aus der Forstlichen Fakultaet der Univ. Goettingen und der Niedersaechsischen Forstlichen Versuchsanstalt, Germany, 1990.

[9] Frobenius G., Über Matrizen aus positiven Elementen, S.-B. Preuss. Akad. Wiss., Berlin, Germany, 1908. 
[10] Gadow K. v., Hui G., Modelling forest development, Faculty of Forest and Woodland Ecology, University of Göttingen, Germany, 1998.

[11] Goñi J.M., Los bosques en Navarra, Departamento de Agricultura, Ganadería y Montes, Gobierno de Navarra, Spain, 1987.

[12] Hein S., Dhôte J-F., Effects of species composition, stand density and site index on the basal area increment of oak trees (Quercus sp.) in mixed stands with beech (Fagus sylvatica L.) in northern France, Ann. For. Sci. 63 (2006) 457-467.

[13] ICONA, Segundo Inventario Forestal Nacional (1986-1995), Ministerio de Agricultura, Pesca y Alimentación (MAPA), Madrid, Spain, 1995.

[14] Jaworsky A., Kolodziej Zb., Natural loss of trees, recruitment and increment in stands of primeval character in selected areas of the Bieszczady Mountains National Park (South-Eastern Poland), J. For. Sci. 48 (2002) 141-149.

[15] Knoke T., Value of complete information on red heartwood formation in beech (Fagus sylvatica), Silva Fenn. 36 (2002) 841-851.

[16] Koop H., Hilgen P., Forest dynamics and regeneration mosaic shifts in unexploited beech (Fagus sylvatica) stands at Fontainebleau (France), For. Ecol. Manage. 20 (1987) 135-150.

[17] Leslie P.H., On the use of matrices in certain population mathematics, Biometrika 33 (1945) 183-212.

[18] Lefkovitch L.P., The study of population growth in organisms grouped by stages, Biometrics 21 (1965) 1-18.

[19] Madrigal A., Puertas F., Martínez Millán J., Tablas de producción para "Fagus sylvatica L." en Navarra, Gobierno de Navarra, Dpto. de Agricultura, Ganadería y Alimentación, Navarra, 1996.

[20] Madsen P., Larsen J.B., Natural regeneration of beech (Fagus sylvatica $\mathrm{L}$.) with respect to canopy density, soil moisture and soil carbon content, For. Ecol. Manage. 97 (1997) 95-105.

[21] Maple version 10.0, Maplesoft, Ontario, Canada, 2005.

[22] Marechal J.P., Bilan des placettes de référence en peuplements irréguliers : réseau, AFI-ENGREF, ENGREF, 1998.

[23] Peng C., Growth and yield models for uneven-aged stands: past, present and future, For. Ecol. Manage. 132 (2000) 259-279.

[24] Perron O., Zur Theorie der Matrizen, Math. Ann. 64 (1907) 248263.

[25] Peterken G.F., Natural woodland. Ecology and conservation in Northern temperate regions, Cambridge University Press, Cambridge, 1996.
[26] Pielou E.C., An Introduction to mathematical ecology, Wiley Interscience, NY, USA, 1969.

[27] Ramula S., Lehtilä K., Matrix dimensionality in demographic analyses of plants: when to use smaller matrices? Oikos 111 (2005) 563-573.

[28] Rozas V., Fernández J.A., Competition, mortality, and development of spatial patterns in two Cantabrian populations of Fagus Sylvatica L. (Fagaceae), Anales Jardín Botánico de Madrid 58 (2000) 117131.

[29] Sanchez-Gonzalez M., Tomé M., Montero G., Modelling height and diameter growth of dominant cork oak trees in Spain, Ann. For. Sci. 62 (2005) 633-643.

[30] Saniga M., Vplyv clony materskeho porastu na pociatocne fazy prirodzenej obnovy buka, Acta Facultatis Forestalis Zvolen 36 (1994) 117-125.

[31] Schütz J.-P., Dynamique et conditions d'équilibre des peuplements jardinés sur les stations de la hêtraie à sapin, Schweiz. Z. Forstwes. 126 (1975) 637-671.

[32] Schütz J.-P., Sylviculture 2, La gestion des forêts irrégulières et melangées, Presses Polytechniques et Universitaires Romandes, Lausanne, Switzerland, 1997.

[33] Schütz J.-P., Demographic sustainability of beech plenter forests, Ann. For. Sci. 63 (2006) 93-100.

[34] Sterba H., Equilibrium curves and growth models to deal with forests in transition to uneven-aged structure - Application in two sample stands, Silva Fenn. 38 (2004) 413-423.

[35] Susmel L., Leggi di varianzione dei parametric della foresta disetanea normale, L'Italia Forestale e Montana XI (1956).

[36] Teissier du Cross E. (Ed.), Le Hêtre, INRA, Paris, 1981.

[37] Timbal J., Répartition en Europe et en France du Hêtre, in: Le Hêtre, Teissier du Cross (Ed.), INRA, Département des Recherches Forestières, Paris, 1981, pp. 58-67.

[38] Van Mantgem P.J., Stephenson N.T., The accuracy of matrix population model projections for coniferous trees in the Sierra Nevada, California, J. Ecol. 93 (2005) 737-747.

[39] Vanclay J.K., Modeling forest growth and yield. Applications to mixed tropical forests, CAB International, Wallingford, UK, 1994.

[40] Zuidema P.A., Demography of exploited tree species in the Bolivian Amazon, PROMAB Scientific Series 2, PROMAB - Riberalta, Bolivia, 2000. 